\title{
PENGATURAN BATAS KEAMANAN SISTEM ALIRAN DAYA OPTIMAL DC MENGGUNAKAN METODE QUADRATIC
}

\section{SETTING THE SECURITY CONSTRAINT OF DC OPTIMAL POWER FLOW SYSTEMS USING QUADRATIC METHOD}

\author{
Santi Triwijaya ${ }^{1}$, Yuli Prasetyo ${ }^{2}$ \\ ${ }^{1}$ Politeknik Perkeretaapian Indonesia, Jalan Tirta Raya I, Nambangan Lor, \\ Mangunharjo, Madiun, Jawa Timur, Indonesia. \\ ${ }_{2}^{2}$ Politeknik Negeri Madiun, Jl. Serayu No 84, Madiun, Jawa Timur, Indonesia.
}

E-mail: santi@ppi.ac.id

Diterima: 18/08/2020; Disetujui: 30/08/2020

\begin{abstract}
ABSTRAK
Gangguan pada sistem saluran transmisi menjadi masalah yang serius. Masalah yang ditimbulkan dapat menjadi penyebab kerusakan bagi saluran transmisi dan distribusi. Gangguan pada sistem transmisi seperti gangguan hubung singkat atau kontingensi saluran. Oleh karena itu perlu upaya untuk menjaga keandalan sistem transmisi. Pengaturan batas keamanan sistem pada aliran daya DC dapat menjadi solusi untuk mengatasi kontingensi sistem. Pengaturan ini menggunakan metode quadratic yang mampu melakukan penjadwalan pembangkit secara optimal ekonomi. Penyelesaian masalah ini menggunakan software Matlab dengan uji coba sistem 9 bus IEEE. Hasil simulasi menunjukkan bahwa metode ini mampu mengatasi kontingensi saluran tanpa melanggar parameter yang ditentukan.
\end{abstract}

Kata Kunci: Kontingensi, Keamanan Sistem, Aliran Daya Optimal DC, Metode Quadratic. 


\begin{abstract}
Disruption in the transmission line system is a serious problem. The problems that arise can cause damage to transmission and distribution lines. Disturbances in transmission systems such as short circuit or line contingency. Therefore it needs efforts to maintain the reliability of the transmission system. Setting the system safety limit on DC power flow can be a solution to overcome system contingencies. This arrangement uses the quadratic method which is able to perform economically optimal generator scheduling. Solving this problem using Matlab software with IEEE 9 bus system trials. The simulation results show that this method is able to overcome channel contingency without violating the specified parameters.
\end{abstract}

Keywords: Contingency, Security Constrains, DC Optimal Power Flow, Quadratic Method. 


\section{PENDAHULUAN}

Gangguan adalah masalah serius dalam penyaluran sistem tenaga listrik. Frekuensi terjadinya gangguan pada saluran transmisi yang paling sering terjadi. Gangguan tersebut berupa gangguan hubung singkat atau kontingensi saluran. Maka perlu suatu perencanaan pembangkitan secara optimal saat sistem mengalami gangguan untuk menjaga keandalan sistem. Optimal Power Flow (OPF) merupakan bentuk pengembangan Economic Dispatch (DE) [1] dengan mempertimbangkan aliran daya pada saluran transmisi. Fungsi dari OPF adalah untuk menjadwalkan pembangkitan generator pada sistem interkoneksi dengan menggunakan studi aliran daya pada saluran sehingga didapat biaya pembangkitan minimal dan tetap memperhatikan batasan atau konstrain yang ada. Batasan tersebut berasal dari batasan daya pembangkitan maksimum-minimum generator, batasan transmisi, dan lain-lain. OPF konvensional hanya digunakan untuk menjadwalkan pembangkitan generator dan tetap memperhatikan batasan atau konstrain yang ada. Namun belum mengatasi masalah jika ada gangguan atau perubahan kondisi, seperti terbukanya cabang jaringan, adanya perubahan beban, dan lain-lain. Efek dari gangguan akan menyebabkan perubahan aliran daya pada cabang-cabang lain, perubahan besar tegangan pada bus-bus lain dan mengurangi lifetime pembangkit. Aliran daya optimal DC dengan mempertimbangkan batasan keamanan sistem merupakan pengembangan dari Optimal Power Flow konvensional dengan memperhitungkan adanya kontingensi pada saluran transmisi dan ramp rate dari unit pembangkit[2]. Fungsi OPF dengan mempertimbangkan batasan keamanan sistem dapat memperhitungkan adanya kontingensi pada saluran transmisi dan memastikan sistem tetap mengalirkan daya listrik dengan memperhatikan batasan keamanan pada sistem tenaga. Dalam OPF dengan mempertimbangkan batasan keamanan sistem, analisis kontingensi digabungkan dengan aliran daya optimal diikuti dengan melakukan beberapa penyesuaian, sehingga tidak ada perubahan saat terjadi gangguan. Studi aliran daya atau load flow merupakan bagian yang sangat penting dalam analisis sistem tenaga[3]. Hasil penjadwalan dengan economic dispatch tidak dapat diterapkan apabila hasil aliran daya pada sistem transmisi ada yang melanggar kapasitas saluran. Salah satu studi aliran daya yang telah banyak digunakan untuk perencaan dan pengembangan studi keamanan sistem tenaga listrik adalah aliran daya arus searah atau DC power flow. Kelebihan DC power flow adalah di sisi waktu perhitungan yang jauh lebih cepat bila dibandingkan dengan AC power flow serta penyederhaan parameter untuk mempermudah analisis sistem. Metode yang digunakan untuk mengatasi permasalahan ini adalah metode qudratic programming. 


\section{METODE}

\subsection{Batas Keamanan Sistem Tenaga}

\section{Listrik}

Menjaga keamanan dalam operasi sistem tenaga listrik merupakan hal yang sangat penting, selain itu juga perlu meminimalisasi biaya operasi. Salah satu tindakan pengamanan sistem tenaga adalah menjaga agar saluran transmisi tidak ada yang mengalami pembebanan lebih. Pembebanan yang berlebihan mengakibat jatuh tegangan. Akibatnya tegangan pada beberapa bus dalam sistem tenaga tersebut menurun. Salah satu faktor penting dalam operasi sistem tenaga listrik adalah keinginan untuk mempertahankan keamanan system. Keamanan sistem meliputi kegiatan yang direncanakan untuk mempertahankan operasi sistem apabila terjadi kegagalan komponen sistem. Kontingensi adalah suatu kejadian yang disebabkan oleh kegagalan dari satu atau lebih pembangkit dan/atau saluran transmisi. Untuk mengevaluasi unjuk kerja dan keandalan sistem tenaga listrik dapat dilakukan dengan menggunakan analisis kontingensi[4]. Analisis ini dilakukan dengan simulasi gangguan pada suatu unit pembangkit atau saluran transmisi dan menyelidiki pengaruh gangguan tersebut terhadap tegangan bus dan aliran daya aktif saluran.

\subsection{Aliran Daya Optimal DC}

Aliran Daya Optimal dengan mempertimbangkan batas keamanan sistem meminimalkan fungsi objektif berupa total biaya pembangkitan generator yang dinyatakan dalam persamaan :

minimize $C=\sum_{i=1}^{T} \sum_{i=1}^{N} F_{i}\left(P_{i t}\right)$

$F_{i}\left(P_{i t}\right)=a_{i} P_{i}^{2}+b_{i} P_{i}+c_{i}$

$\mathrm{T}$ adalah jumlah level beban, $\mathrm{N}$ adalah jumlah generator, $\mathrm{Pi}$ adalah daya keluaran dari unit $\mathrm{i}$ dan $\mathrm{a}, \mathrm{b}$ dan $\mathrm{c}$ adalah cost coefficient unit generator ke $\mathrm{i}$.

Fungsi Objektif ini diminimalkan melalui batasan - batasan sebagai berikut :

1. Active Power Balance Constraint

$$
\begin{aligned}
& P_{G i}^{0}-P_{D i}^{0}-P_{I N i}^{0}=0 \\
& P_{I N i}^{0}=\sum F_{i j}^{0}=\sum \frac{1}{x_{i j}}\left[\theta_{i}-\theta_{j}\right]
\end{aligned}
$$

$\mathrm{P}_{\mathrm{D}}, \mathrm{P}_{\mathrm{G}}, \mathrm{P}_{\mathrm{IN}}$ adalah daya beban, daya generator dan daya saluran. $\mathrm{X}$ ij adalah reaktansi saluran ij. $\theta$ merupakan sudut tegangan.

2. Active Power Flow Constraint

$$
\left|F_{i j}^{0}\right| \leq F_{i j}^{U}
$$

F ij merupakan kapasitas saluran ij (MVA)

3. Capacity Constraint dan Voltage Angle Constraint

$$
\begin{aligned}
& P_{G i}^{L 0} \leq P_{G i}^{0} \leq P_{G i}^{U 0} \\
& \theta_{i}^{L} \leq \theta_{i} \leq \theta_{i}^{U}
\end{aligned}
$$

$P_{G i}^{L 0}, P_{G i}^{U 0}$ merupakan kapasitas pembangkit minimum dan maksimum dari generator 


\subsection{Quadratic Programming[4]}

Metode quadratic digunakan untuk mengatasi permasalahan aliran daya optimal. Variabel permasalahan aliran daya optimal adalah $\mathrm{x}$.

$x=\left[\begin{array}{c}\theta_{i} \\ P_{G i}\end{array}\right]$

Fungsi objektif :

$F_{i}\left(P_{i}\right)=\frac{1}{2} x^{T} H x+G^{T} x$

Constraint sistem linier :

$l b \leq A x \leq u b$

$x_{\min } \leq x \leq x_{\max }$

$\mathrm{G}, \mathrm{H}$, dan A merupakan matrik, lb, ub, $\mathrm{x}_{\min }$, $\mathrm{x}_{\text {mak }}$ dan $\mathrm{x}$ adalah vektor.

$-D \leq C C R * x \leq D$

$\mathrm{P}$ adalah daya aktif pembangkit dan $\mathrm{D}$ adalah ramp rate.

Pembentukan vector $\mathrm{lb}$ da nub sebagai batas dari constraint sebagai berikut:

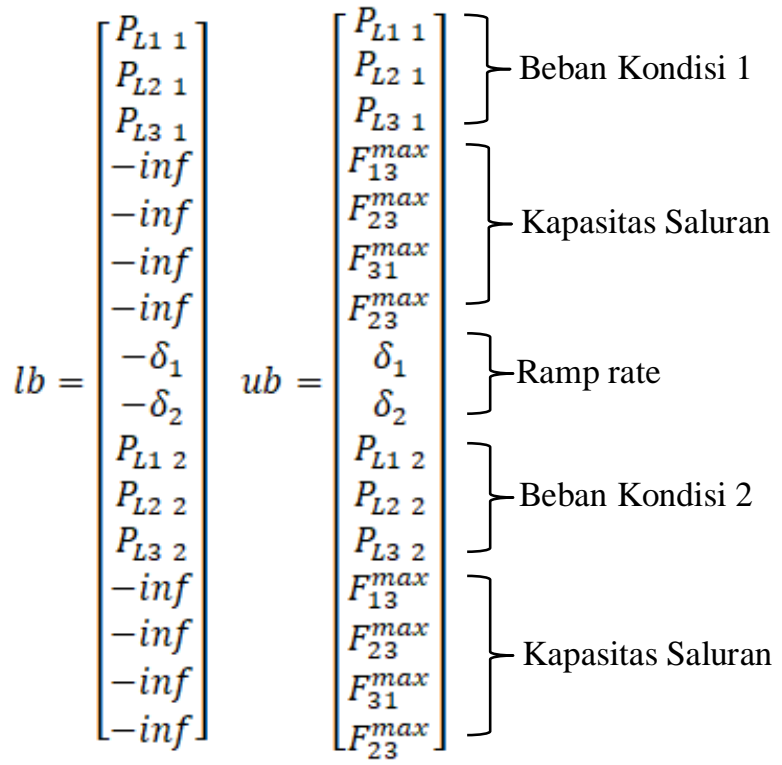

\section{HASIL PENELITIAN DAN PEMBAHASAN}

Pada tahap hasil dan pembahasan dilakukan pengujian pada sistem untuk memperoleh data. Analisis kontingensi dari sistem IEEE 9 bus digunakan untuk mengetahui saluran yang memiliki dampak terbesar dalam sistem. Hasil pengaruh kontingensi pada system IEEE 9 bus dapat dilihat pada tabel 1 .

Tabel 1.

Dampak kontingensi di Sistem IEEE 9 Bus

\begin{tabular}{|c|c|c|c|c|}
\hline Urutan & Saluran & $\begin{array}{c}\text { From } \\
\text { Bus }\end{array}$ & $\begin{array}{c}\text { Ke } \\
\text { Bus }\end{array}$ & Biaya (\$) \\
\hline 1 & 7 & 8 & 2 & 15242,16 \\
\hline 2 & 9 & 9 & 4 & 13463,53 \\
\hline 3 & 1 & 1 & 4 & 13463,53 \\
\hline 4 & 4 & 3 & 6 & 13463,53 \\
\hline 5 & 3 & 5 & 6 & 13463,53 \\
\hline 6 & 2 & 4 & 5 & 13463,53 \\
\hline 7 & 5 & 6 & 7 & 13463,53 \\
\hline 8 & 6 & 7 & 8 & 13463,53 \\
\hline 9 & 8 & 8 & 9 & 13463,53 \\
\hline
\end{tabular}

Tabel 2.

Daya Pembangkit Tanpa Ramp-rate

\begin{tabular}{|c|c|c|c|c|c|}
\hline \multirow[b]{2}{*}{$\begin{array}{c}\text { Unit } \\
\text { Pembangkit }\end{array}$} & \multirow[b]{2}{*}{$\begin{array}{l}\text { Ramp } \\
\text { rate }\end{array}$} & \multicolumn{2}{|c|}{$\begin{array}{c}\text { Tanpa Ramp- } \\
\text { rate }\end{array}$} & \multicolumn{2}{|c|}{ OPF } \\
\hline & & $\begin{array}{c}\text { Kondisi } \\
1 \\
\text { (MW) }\end{array}$ & $\begin{array}{c}\text { Kondisi } \\
2 \\
\text { (MW) }\end{array}$ & $1-2$ & Ket \\
\hline 1 & 20 & 155,64 & 185,53 & 29.89 & $\begin{array}{c}\text { Tdk } \\
\text { sesuai }\end{array}$ \\
\hline 2 & 25 & 223,77 & 115,2 & 108.5 & $\begin{array}{l}\text { Tdk } \\
\text { sesuai }\end{array}$ \\
\hline 3 & 40 & 156,09 & 234,77 & 78.68 & $\begin{array}{c}\text { Tdk } \\
\text { sesuai }\end{array}$ \\
\hline
\end{tabular}

Pengujian ini untuk mengetahui pengaruh dari metode quadratic programming yang akan digunakan untuk analisa aliran daya optimal. Ada 2 kondisi pada pengujian ini yaitu Kondisi 1 (saat Normal), Kondisi 2 (saat terjadi kontingensi pada saluran bus 8 
ke bus 2). Tabel 2 menunjukkan hasil daya pembangkit yang digunakan tanpa adanya batasan ramp-rate.

Tabel 3.

Daya Pembangkit Dengan Ramp-rate

\begin{tabular}{|c|c|c|c|c|c|}
\hline \multirow{2}{*}{$\begin{array}{c}\text { Unit } \\
\text { Pembangkit }\end{array}$} & \multirow{2}{*}{$\begin{array}{c}\text { Ramp- } \\
\text { rate }\end{array}$} & \multicolumn{2}{|c|}{$\begin{array}{c}\text { Dengan Ramp- } \\
\text { rate }\end{array}$} & \multicolumn{2}{c|}{ OPF } \\
\cline { 3 - 6 } & & $\begin{array}{c}\text { Kondisi } \\
1(\mathrm{MW})\end{array}$ & $\begin{array}{c}\text { Kondisi } \\
2(\mathrm{MW})\end{array}$ & $1-2$ & Ket \\
\hline 1 & 20 & 195,5 & 194,88 & 9.31 & sesuai \\
\hline 2 & 25 & 150 & 125 & 1.86 & sesuai \\
\hline 3 & 40 & 190 & 215,62 & 7.45 & sesuai \\
\hline
\end{tabular}

Tabel 3 menjelaskan hasil dari daya pembangkit yang menggunakan batasan Ramp-rate. Analisa aliran daya tanpa constraint ramp rate terjadi pelanggaran batas ramp rate pada semua unit. Analisa aliran daya dengan constraint ramp rate menghasilkan semua batasan ramp rate terpenuhi dan tidak ada pelanggaran. Hal ini membuktikan bahwa aliran daya optimal dapat digunakan untuk membuat pembangkitan yang optimal tanpa melewati batasan ramp rate walaupun terjadi kontingensi.

\section{KESIMPULAN}

Dari hasil simulasi diperoleh kesimpulan program optimal power flow arus searah dengan mempertimbangkan batasan keamanan sistem (SCDC OPF) menggunakan quadratic programming dapat melakukan perhitungan penjadwalan pembangkitan dalam rentang waktu tertentu tanpa melanggar batasan berupa ramp constraint dan kapasitas saluran. Batasan kapasitas saluran berpengaruh pada pengaturan pembangkitan generator menjadi lebih komplek untuk menjaga agar saluran tidak mengalami kerusakan akibat aliran daya yang berlebih. Batasan ramp constraint berpengaruh pada pengaturan pembangkitan generator menjadi lebih komplek. Kontingensi saluran menyebabkan perubahan penjadwalan dalam optimal power flow dan menghasilkan biaya pembangkitan yang lebih mahal jika dibandingkan dengan kondisi normal. 


\section{DAFTAR PUSTAKA}

[1] V. H. Kumar, P. S. Varma, T. B. Kumar, and E. Sreelatha, "Economic and Emission Dispatch Problem using Particle Swarm Optimization," vol. 8, no. 6, p. 6, 2019.

[2] S. Triwijaya, N. Sugiantoro, Y. Prasetyo, Firdaus, R. S. Wibowo, and O. Penangsang, "Security Constrained Optimal Power Flow Considering Dynamic Line Rating," in 2018 10th International Conference on Information Technology and Electrical Engineering (ICITEE), Kuta, Jul. 2018, pp. 4651, doi: 10.1109/ICITEED.2018.8534755.

[3] Y. Prasetyo, A. C. Arifin, and T. Multazam, "Analisis Rekonfigurasi Dan Penempatan Kapasitor Untuk Meminimalkan Deviasi Tegangan Pada Sistem Distribusi," vol. 01, no. 02, p. 10, 2018.

[4] N. A. Taghi-Nezhad and F. Taleshian, "A Solution Approach for Solving Fully Fuzzy Quadratic Programming Problems," J. Appl. Res. Ind. Eng., vol. 5, no. 1, Jun. 2018, doi: 10.22105/jarie.2018.111797.1028. 